Annales Geophysicae (2002) 20: 1891-1898 (C) European Geosciences Union 2002

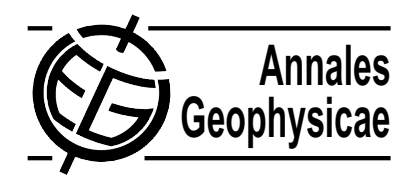

\title{
Cloud microphysical characteristics versus temperature for three Canadian field projects
}

\author{
I. Gultepe, G. A. Isaac, and S. G. Cober \\ Cloud Physics Research Division, MSC/ARMP , 4905 Dufferin St. Downsview, Ontario M3H-5T4, Canada
}

Received: 30 November 2001 - Revised: 7 May 2002 - Accepted: 4 June 2002

\begin{abstract}
The purpose of this study is to better understand how cloud microphysical characteristics such as liquid water content (LWC) and droplet number concentration $\left(N_{d}\right)$ change with temperature $(T)$. The in situ observations were collected during three research projects including: the Radiation, Aerosol, and Cloud Experiment (RACE) which took place over the Bay of Fundy and Central Ontario during August 1995, the First International Regional Arctic Cloud Experiment (FIRE.ACE) which took place in the Arctic Ocean during April 1998, and the Alliance Icing Research Study (AIRS) which took place in the Ontario region during the winter of 1999-2000. The RACE, FIRE.ACE, and AIRS projects represent summer mid-latitude clouds, Arctic clouds, and mid-latitude winter clouds, respectively. A LWC threshold of $0.005 \mathrm{~g} \mathrm{~m}^{-3}$ was used for this study. Similar to other studies, LWC was observed to decrease with decreasing $T$. The LWC- $T$ relationship was similar for all projects, although the range of $T$ conditions for each project was substantially different, and the variability of LWC within each project was considerable. $N_{d}$ also decreased with decreasing $T$, and a parameterization for $N_{d}$ versus $T$ is suggested that may be useful for modeling studies.
\end{abstract}

Key words. Atmospheric composition and structure (cloud physics and chemistry) - Meteorology and atmospheric dynamics (climatology; general circulation)

\section{Introduction}

Clouds in the atmosphere consist of liquid, ice, or mixed phase particles and their effect on climate is primarily influenced by the amount of water within the clouds. Over the last decade, it has been recognized that one of the major uncertainties in the modeling of climate is the representation of the cloud physical and optical characteristics (Lemus et al., 1997; Kiehl and Ramanathan, 1990; Smith, 1990; Gul-

Correspondence to: I. Gultepe

(ismail.gultepe@ec.gc.ca) tepe et al., 2001a). Hence, there has been considerable focus on characterizing clouds, both directly with in situ measurements, and indirectly with various remote sensing instruments. The accuracy of in situ measurements of liquid water content (LWC) and droplet number concentration $\left(N_{d}\right)$ is better than those obtained from satellite or radar derived measurements. The reason is that the remote sensing methods assume a particle size distribution and/or constant $N_{d}$ for their inversion technique, which may not represent the real cloud systems. For these reasons, in situ observations of cloud microphysical parameters have been intensively studied (e.g. Platt, 1989; Gultepe et al., 1996) for application to climate investigations. Korolev et al. (2001) and Gultepe et al. (2001b) studied microphysical properties of continental stratiform and maritime clouds, respectively, and showed that the cloud extinction parameter that is widely used in climate simulations could be very sensitive to changes in microphysical parameters.

The cloud LWC is a main parameter for estimating condensational heating rates in meso-scale models (Meyers et al., 1992) or radiative heating rates in general circulation models (GCMs) (Slingo and Schrecker, 1982; DelGenio et al., 1996). Rotstayn (1999a; 1999b) used a global climate model to study the indirect radiative forcing due to modifications in liquid cloud properties. He found that indirect radiative forcing of about $-2.1 \mathrm{~W} \mathrm{~m}^{-2}$ results from a $1 \%$ increase in cloudiness, a $6 \%$ increase in liquid water path, and a $7 \%$ decrease in effective radius. This suggests that uncertainty in LWC obtained from empirical relationships is important for climate sensitivity studies.

Many earlier studies have used the Feigelson (1978) results to study cloud-climate interactions. However, this is not suitable for GCM studies because she used a relatively high value of LWC $\left(0.05 \mathrm{~g} \mathrm{~m}^{-3}\right)$ as a lower threshold (Liou and Ou, 1989). Gultepe and Isaac (1997), hereafter GI, showed that the average LWC observed in several Canadian field projects was less than $50 \%$ of the values suggested by Feigelson (1978). Mazin (1995) suggested a total water content (TWC)-temperature (T) relationship that was similar to 
those of GI at warm temperatures.

Using observations derived from GI, Rasch and Kristjansson (1998) made comparisons between observed values from GI and the National Center for Atmospheric Research (NCAR) Community Climate Model (CCM3) simulations based on a prognostic equation for LWC. They found that the results from their prognostic equations represent cloud LWC much better than earlier simulations after making comparisons with observed in situ data. Using satellite and microwave radiometer (MWR) measurements, DelGenio et al. (2000) suggested that there was no observed relationship between LWC and $T$ for winter or summer clouds, and that in situ measurements would be useful for verifying the results if they were available. These studies suggest that LWC versus $T$ relationships are not consistently represented in cloudclimate studies.

At present, there are several questions that need to be addressed: (1) Does LWC change with $T$ ?, (2) What are the differences in LWCs if comparisons are made with earlier studies ?, (3) How different are LWC- $T$ relationships for different cloud systems, e.g. winter clouds versus summer clouds, or Arctic clouds versus mid-latitude clouds ?, and (4) Is there a relationship between $N_{d}$ and temperature ? In the present study, in situ observations from three Canadian research projects, representing seasonal and geographic changes, are studied to better understand LWC-T and $N_{d}-T$ relationships.

\section{Observations}

The in situ observations were collected with instruments mounted on the National Research Council (NRC) Convair580 aircraft during the Radiation, Aerosol, and Cloud Experiment (RACE; Gultepe et al., 2001b), the First International Regional Arctic Cloud Experiment (FIRE.ACE; Gultepe and Isaac, 2002), and the Alliance Icing Research Study (AIRS; Isaac et al., 2001). These projects took place over the Bay of Fundy and Central Ontario during August 1995, in the Arctic Ocean during April 1998, and in the Ontario region during the winter of 1999-2000, respectively. RACE, FIRE.ACE, and AIRS represent mid-latitude summer clouds, Arctic clouds, and mid-latitude winter clouds, respectively. The vast majority of the clouds sampled were stratiform (e.g. stratus, stratocumulus, altostratus, cirrostratus, etc.).

The 1-s observations of LWC, droplet number concentration $\left(N_{d}\right)$, and $\mathrm{T}$ are used in deriving the relationships. The LWC and $N_{d}$ are obtained from hot wire probes (Nevzorov and King probes) and Forward Scattering Spectometer Probes (FSSP), respectively. A Rosemount Icing Detector (RID) was used to segregate regions with supercooled liquid water from glaciated regions (Cober et al., 2001a). The Nevzorov hot wire probes are discussed in Korolev et al. (1998). The $N_{d}$ is obtained from FSSP-100 probes with size ranges of either 3-45 $\mu \mathrm{m}$ or 5-95 $\mu \mathrm{m}$. Uncertainties in LWC and $N_{d}$, can be about $15 \%$ (Cober et al., 2001b) and 30\% (Baumgardner et al., 1990), respectively. The $T$ measurements were obtained from both Rosemount and reverse flow $T$ probes with an accuracy of about $1^{\circ} \mathrm{C}$.

The field projects used in this work are different than those used in Gultepe and Isaac (1997). In their work, observations were collected during the North Atlantic Regional Experiment (NARE), the Second Canadian Atlantic Storms Program (CASP II), the Eulerian Model Evaluation Field Studies (EMEFS I and II), and the Syracuse field project. Cloud systems from GI represent both thin and thick stratiform clouds.

\section{Analysis}

At cold $T$ values, liquid, mixed phase, and glaciated regions were identified following the method given in Cober et al. (2001b). Combinations of RID signals, $N_{d}$, ice crystal number concentration $\left(N_{i}\right)$, and LWC were used for identifying and segregating liquid, mixed and glaciated phase regions. For AIRS 1-s data, the percentages of liquid, mixed phase, and glaciated cloudy conditions are about 33\%, 48\%, and $19 \%$, respectively, and these numbers include an uncertainty of about $12 \%$, based on an uncertainty of $0.005 \mathrm{~g} \mathrm{~m}^{-3}$ in LWC. These percentages are comparable with those given in Isaac et al. (2001). For RACE and FIRE.ACE, the percentage of mixed phased cases is significantly less than for AIRS. The reason is that FIRE data were collected in boundary layer ice clouds, and that RACE data were collected in predominantly liquid phase clouds. For this paper, the mixed phase and glaciated clouds have been removed from the analysis, leaving only the all liquid regions. This helps eliminate uncertainties associated with identifying the liquid portions of mixed phase clouds, and the difficulties of sizing cloud particles within mixed phase clouds.

The analysis of LWC and $N_{d}$ versus $T$ is performed using averages of $\mathrm{LWC}$ and $N_{d}$ at $5^{\circ} \mathrm{C}$ temperature intervals for each field project. This $T$ interval is chosen to be consistent with other studies and to decrease the effect of variability on the averaged parameters. In addition, the frequency of occurrence values of $\mathrm{LWC}$ for $0.02 \mathrm{~g} \mathrm{~m}^{-3}$ bins at each temperature interval were calculated. The lower limit of LWC for the 1-s measurements is considered to be $0.005 \mathrm{~g} \mathrm{~m}^{-3}$. Finally, the mean, standard deviation (sd), and median values, as well as the number of points used for each interval, are determined to show the variability in LWC. The $N_{d}$ values collected at a 1-s sampling rate are also presented to illustrate possible relationships between $N_{d}$ and $T$.

\section{Results and discussions}

\subsection{LWC-T relationships}

In this section, the frequency of occurrence values of LWC are determined for $5^{\circ} \mathrm{C}$ intervals. Then, the profiles of mean and median values for each project (Tables 1 and 2) are compared with those of GI. 


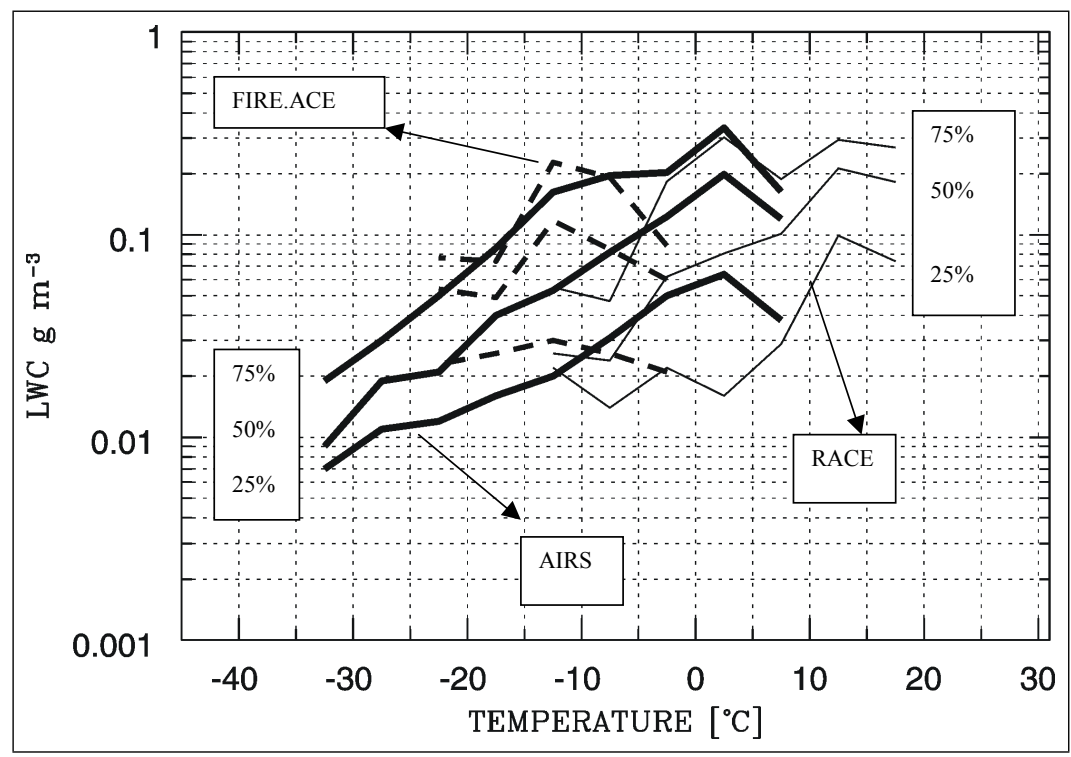

Fig. 1. Frequency of occurrence of LWC over $5^{\circ} \mathrm{C}$ intervals versus $T$ for each project. Each set of curves includes the 25,50 , and 75 percentiles.

The frequencies of occurrence of LWC for RACE, AIRS, and FIRE.ACE are shown in Fig. 1. Overall, the median (50\%) values of LWC from RACE decreases with decreasing T. A decrease in LWC with increasing $T$ observed at the warmest temperature is associated with cloud bases and the lack of observations at warmer temperatures. This trend is seen for each individual field project (Fig. 1). For AIRS, the $50 \%$ values (median) of LWC also decreases with decreasing $T$. Figure 1 also shows that percentile values reach maximum values at about $12^{\circ} \mathrm{C}$ for RACE, $2^{\circ} \mathrm{C}$ for AIRS, and $-12^{\circ} \mathrm{C}$ for FIRE.ACE. This reflects the average incloud temperature or the statistics of cloud sampling for each project. Overall, the trends of these curves are similar to each other, indicating that LWC decreases with decreasing temperature. LWC values less than $0.005 \mathrm{~g} \mathrm{~m}^{-3}$ should not be considered significant due to instrument limitations. For each project, the individual LWC values show significant fluctuations around the mean values.

Comparisons between the results of the present study and earlier studies (e.g. Gultepe and Isaac, 1997; Mazin, 1995, and Feigelson, 1978) are given in Figs. 2 and 3, and the data from this study are given in Tables 1 and 2. In the tables, mean, sd, median, $25 \%$ and $75 \%$ values are shown for each field project to demonstrate the variability in a given $T$ interval. The tables show that measurements were made over different temperature ranges for each project. A comparison between the mean values within each temperature interval shows excellent agreement, within one sd, when significant numbers of data points are available. The bars in Fig. 2 show the relative variability from GI's work. The line at the far right is for the upper limit of LWC $(\mathrm{LWC}+\mathrm{sd})$ of GI. The lower limit used for the present study was $0.005 \mathrm{~g} \mathrm{~m}^{-3}$ which is less than the value $0.01 \mathrm{~g} \mathrm{~m}^{-3}$ that was used in the earlier studies. Because of this, it is likely that the average LWC values in the current study are slightly less than those of the earlier studies. The AIRS data were well correlated with GI.

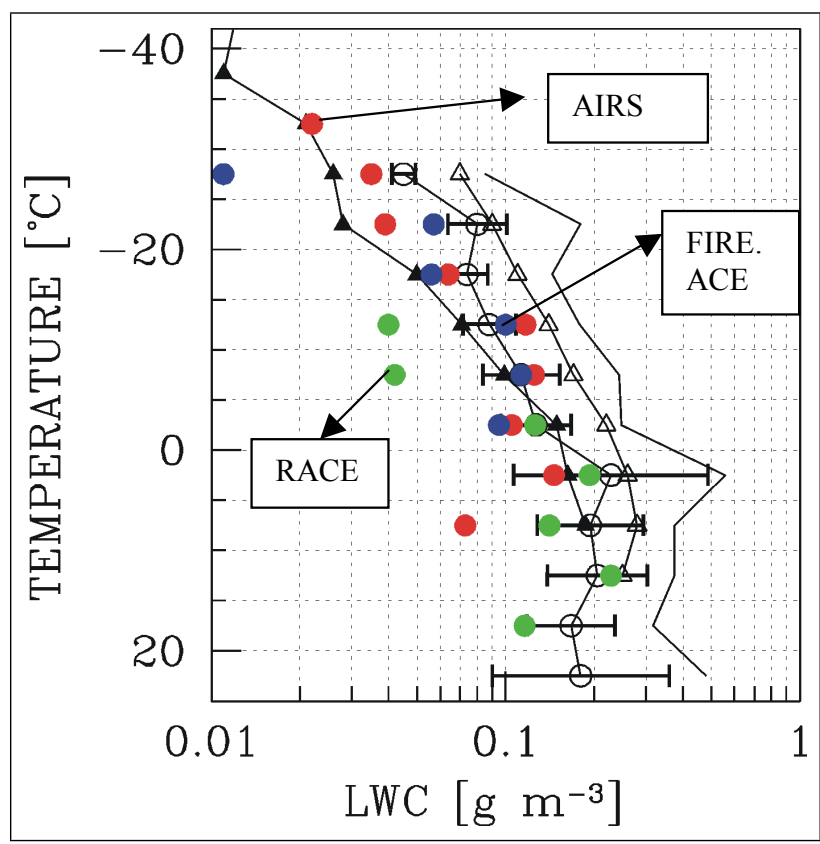

Fig. 2. Profiles of LWC versus $T$ at $5^{\circ} \mathrm{C}$ intervals; solid triangles are from Mazin (1995) for total water content, blank triangles are for Feigelson (1978) for LWC, blank circles are for Gultepe et al. (1997) for LWC. The bars show relative variability in LWC from GI. The solid line at the far right represents mean+sd of LWC from GI.

For cold clouds, LWC values from FIRE.ACE are found to be comparable to those of earlier studies. Note that some data points at cold temperatures $\left(T<-5^{\circ} \mathrm{C}\right)$ during RACE should not be considered as significant due to the lack of observations.

Figure 3 shows median values from the present study and from GI. Because a lower limit for the LWC calculation was used, the median values at cold temperatures from the present 
Table 1. Mean, standard deviation (sd), and number of points (np) used in the calculations for $\Delta T=5^{\circ} \mathrm{C}$ intervals for all projects

\begin{tabular}{c|c|c|c|c|c|c|c|c|c}
\hline & \multicolumn{3}{|c|}{ RACE } & \multicolumn{3}{c|}{ FIRE.ACE } & \multicolumn{3}{c}{ AIRS } \\
\hline $\begin{array}{c}T \\
{\left[{ }^{\circ} \mathrm{C}\right]}\end{array}$ & $\begin{array}{c}\text { mean } \\
\mathrm{g} \mathrm{m}^{-3}\end{array}$ & $\begin{array}{c}\mathrm{sd} \\
\mathrm{g} \mathrm{m}^{-3}\end{array}$ & $\mathrm{np}$ & $\begin{array}{c}\text { mean } \\
\mathrm{g} \mathrm{m}^{-3}\end{array}$ & $\begin{array}{c}\mathrm{sd} \\
\mathrm{g} \mathrm{m}^{-3}\end{array}$ & $\mathrm{np}$ & $\begin{array}{c}\text { mean } \\
\mathrm{g} \mathrm{m}^{-3}\end{array}$ & $\begin{array}{c}\mathrm{sd} \\
\mathrm{g} \mathrm{m}^{-3}\end{array}$ & $\mathrm{np}$ \\
\hline 17.5 & 0.116 & 0.110 & 1788 & & & & & & \\
\hline 12.5 & 0.228 & 0.165 & 7806 & & & & & & \\
\hline 7.5 & 0.141 & 0.159 & 5555 & & & & 0.113 & 0.073 & 27 \\
\hline 2.5 & 0.193 & 0.238 & 2352 & & & & 0.207 & 0.146 & 4490 \\
\hline-2.5 & 0.126 & 0.155 & 3083 & 0.095 & 0.110 & 53 & 0.139 & 0.105 & 10259 \\
\hline-7.5 & 0.042 & 0.054 & 600 & 0.113 & 0.094 & 1487 & 0.128 & 0.125 & 24210 \\
\hline-12.5 & 0.042 & 0.030 & 128 & 0.101 & 0.103 & 1884 & 0.105 & 0.117 & 4430 \\
\hline-17.5 & & & & 0.056 & 0.038 & 2687 & 0.064 & 0.067 & 4170 \\
\hline-22.5 & & & & 0.057 & 0.035 & 2028 & 0.039 & 0.044 & 1275 \\
\hline-27.5 & & & & & & & 0.035 & 0.050 & 980 \\
\hline-32.5 & & & & & & & 0.022 & 0.034 & 302 \\
\hline-37.5 & & & & & & & 0.006 & 0.010 & 45 \\
\hline
\end{tabular}

Table 2. $25 \%, 50 \%$ (median), and $75 \%$ values of $\mathrm{LWC}$ at $\Delta T=5^{\circ} \mathrm{C}$ intervals for all projects

\begin{tabular}{c|c|c|c|c|c|c|c|c|c}
\hline & \multicolumn{3}{|c|}{ RACE } & \multicolumn{3}{c|}{ FIRE.ACE } & \multicolumn{3}{c}{ AIRS } \\
\hline \begin{tabular}{c}
\hline \\
{$\left[{ }^{\circ} \mathrm{C}\right]$}
\end{tabular} & $\begin{array}{c}25 \% \\
\mathrm{~g} \mathrm{~m}^{-3}\end{array}$ & $\begin{array}{c}50 \% \\
\mathrm{~g} \mathrm{~m}^{-3}\end{array}$ & $\begin{array}{c}75 \% \\
\mathrm{~g} \mathrm{~m}^{-3}\end{array}$ & $\begin{array}{c}25 \% \\
\mathrm{~g} \mathrm{~m}^{-3}\end{array}$ & $\begin{array}{c}50 \% \\
\mathrm{~g} \mathrm{~m}^{-3}\end{array}$ & $\begin{array}{c}75 \% \\
\mathrm{~g} \mathrm{~m}^{-3}\end{array}$ & $\begin{array}{c}25 \% \\
\mathrm{~g} \mathrm{~m}^{-3}\end{array}$ & $\begin{array}{c}50 \% \\
\mathrm{~g} \mathrm{~m}^{-3}\end{array}$ & $\begin{array}{c}75 \% \\
\mathrm{~g} \mathrm{~m}^{-3}\end{array}$ \\
\hline 17.5 & 0.074 & 0.182 & 0.270 & & & & & & \\
\hline 12.5 & 0.099 & 0.212 & 0.294 & & & & & & \\
\hline 7.5 & 0.029 & 0.101 & 0.188 & & & & 0.038 & 0.120 & 0.163 \\
\hline 2.5 & 0.016 & 0.081 & 0.302 & & & & 0.064 & 0.199 & 0.337 \\
\hline-2.5 & 0.022 & 0.062 & 0.183 & 0.021 & 0.060 & 0.088 & 0.050 & 0.123 & 0.203 \\
\hline-7.5 & 0.014 & 0.024 & 0.047 & 0.026 & 0.085 & 0.193 & 0.031 & 0.082 & 0.196 \\
\hline-12.5 & 0.022 & 0.026 & 0.055 & 0.030 & 0.117 & 0.228 & 0.020 & 0.053 & 0.162 \\
\hline-17.5 & & & & 0.026 & 0.049 & 0.074 & 0.016 & 0.040 & 0.086 \\
\hline-22.5 & & & & 0.023 & 0.054 & 0.077 & 0.012 & 0.021 & 0.050 \\
\hline-27.5 & & & & & & & 0.011 & 0.019 & 0.030 \\
\hline-32.5 & & & & & & & 0.007 & 0.009 & 0.019 \\
\hline
\end{tabular}

work are smaller in comparison to those of GI. The AIRS data matched well with GI except at $T<-25^{\circ} \mathrm{C}$. The RACE data were also within the range of $20 \%$ and $80 \%$ of GI.

The results from the present study indicate that LWC variability, as a function of $T$, can be significant (Figs. 2 and 3 ). LWC can be substantially different for cold clouds, e.g. Arctic clouds during spring and winter, as compared to warm clouds. This implies that the results of Feigelson (1978) that are used by other parameterizations (Betts and Harshvardhan, 1987) can result in a large uncertainty $(>50 \%)$ in LWC for the cloud net radiation effect calculations that go into earth energy budget estimations in GCMs. For example, based on Fig. 2, it is estimated that LWC uncertainty can be about $0.05 \mathrm{~g} \mathrm{~m}^{-3}$ when the results of GI and Feigelson (1987) are compared.

The DelGenio and Wolf (2000) method that was based on satellite observations did not detect LWC at $T$ less than about $-10^{\circ} \mathrm{C}$. Conversely, the observations used in the present work indicate that approximately $40-50 \%$ of in-cloud points at temperatures less than $-10^{\circ} \mathrm{C}$ contained liquid water. This suggests that liquid phase conditions at $T<-10^{\circ} \mathrm{C}$ cannot be neglected when establishing LWC- $T$ relationships. The mean LWC values from DelGenio and Wolf (2000), of 0.1 to $0.2 \mathrm{~g} \mathrm{~m}^{-3}$ at about $0^{\circ} \mathrm{C}$, were comparable with the results of the present work.

For LWC versus $T$ relationships, the averaging scales are 


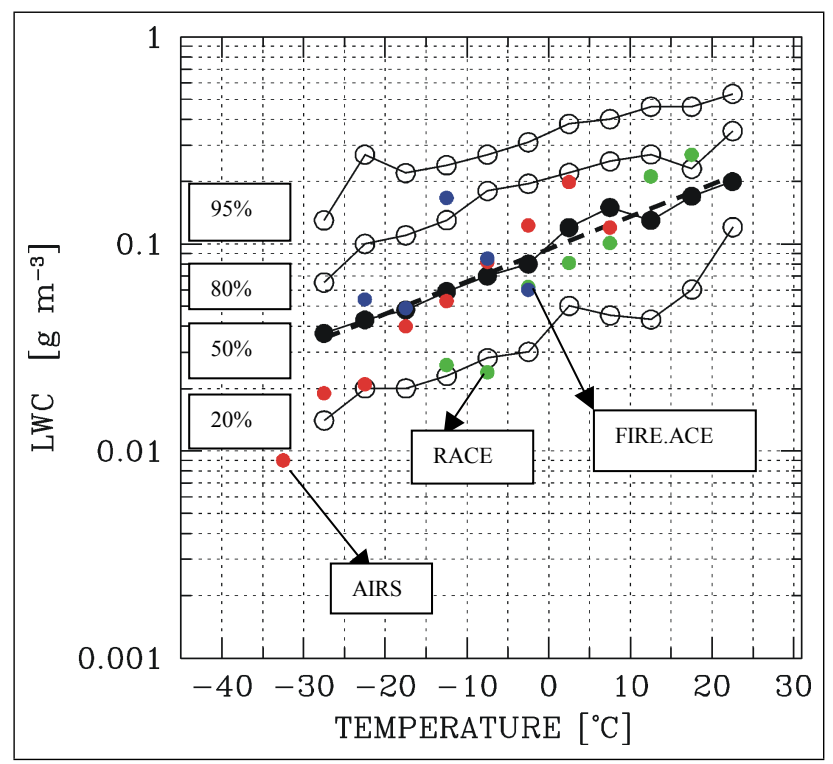

Fig. 3. Median values of LWC compared with the results of GI. The black circles are for median values of LWC from Gultepe and Isaac (1997). The dashed line is a fit to the median values of GI.

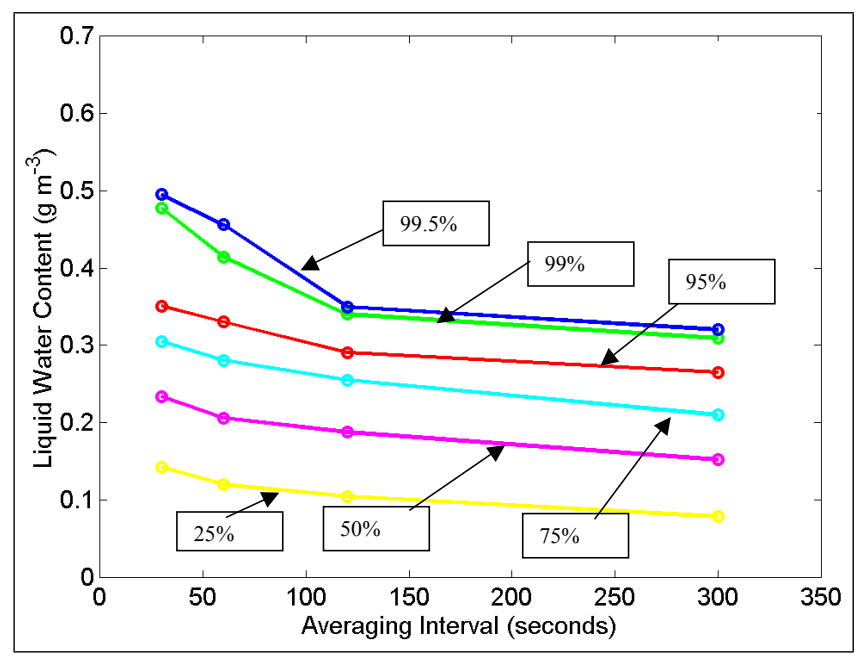

Fig. 4. Relationship between averaged LWC and averaging scale for different percentiles for the AIRS data set. The Convair-580 flies at approximately $100 \mathrm{~m} \mathrm{~s}^{-1}$, which means the $30-\mathrm{s}, 60-\mathrm{s}, 120-\mathrm{s}$, and 300 -s averages represent scales of $3 \mathrm{~km}, 6 \mathrm{~km}, 12 \mathrm{~km}$, and $30 \mathrm{~km}$, respectively.

important when computing mean LWC values. This problem was also discussed in Gultepe and Isaac (1999). Figure 4 shows that, when the averaging scale increases by a factor of 10, LWC decreases significantly for all percentiles. In the present work, 1-s observations are used in the calculations, indicating that measurements represent a scale of approximately $100 \mathrm{~m}$.

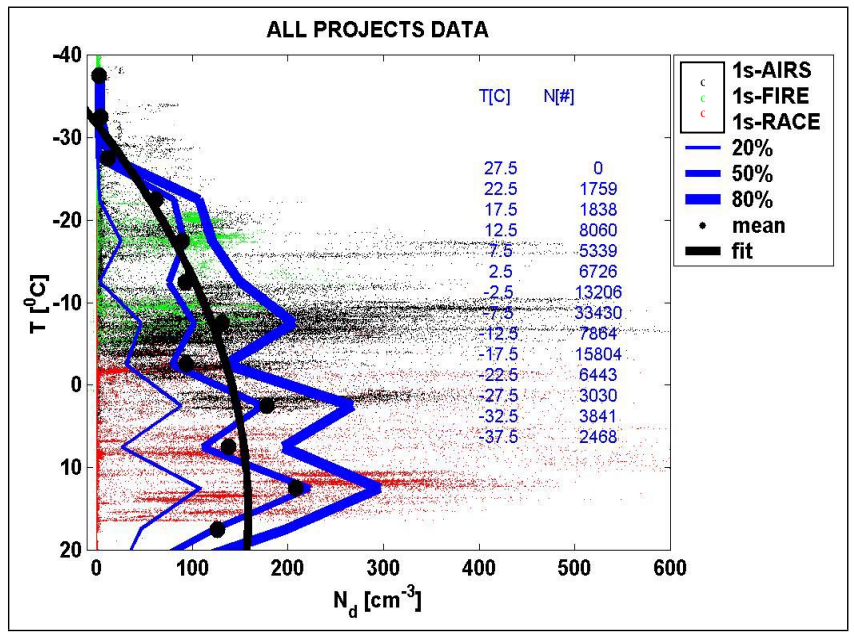

Fig. 5. Scatter plots of FSSP-100 concentrations for the 5-95 $\mu \mathrm{m}$ interval versus $T$, for all field projects. Mean, median, and percentile values (filled circles) are indicated in the legend. The number of points versus $T$ is also shown on the figure. The color points are for 1-s data from AIRS, RACE, and FIRE.ACE. The solid line is for the best fit (Eq. 2) to the mean values.

\section{2 $\quad N_{d}-T$ relationships and effective radius}

The $N_{d}$ versus $T$ relationships can also be important for climate studies where microphysical and optical parameters are parameterized. Figure 5 shows that $N_{d}$ decreases with decreasing $T$ for the 1-s observations of data from all field projects. The variability in $N_{d}$ values from various field projects can be related to aerosol number concentrations $\left(N_{a}\right)$, dynamics of the cloud systems, and thermodynamical properties of the environment. Using aircraft observations, Gultepe and Isaac (1999) and Ghan et al. (1993) showed that droplet number concentration increased with both increasing aerosol number concentration and vertical air velocity. $N_{d}$ measurements during the FIRE.ACE project were collected in an Arctic environment that was completely different than that of the RACE project. The $T$ interval for FIRE.ACE was primarily between -5 and $-30^{\circ} \mathrm{C}$, while the $T$ values for RACE were greater than $-5^{\circ} \mathrm{C}$ in the maritime boundary layer clouds. Most of the data from AIRS were collected between 0 and $-30^{\circ} \mathrm{C}$ in winter storms. The different airmass origins for these data sets result in a large variation at any given level in Fig. 5. Dynamical and thermodynamical effects on cloud LWC are much larger than aerosol effects but the aerosol effect becomes important for $N_{d}$. A decrease at warmer temperatures is likely related to a lack of observations and the proximity to the cloud base.

It is very common for LWC- $T$ profiles at $5^{\circ} \mathrm{C}$ intervals to be used in GCM calculations. A similar approach for $N_{d^{-}}$ $T$ profiles can also be performed if a relationship exists between $N_{d}$ and $T$. This relationship could then be used to obtain $r_{\text {eff }}$ in large-scale models. If both LWC and $N_{d}$ change with decreasing $T$, then, $r_{\text {eff }}$ should also change. In this case, a change in $r_{\text {eff }}$ is related to a change in both LWC and $N_{d}$, 


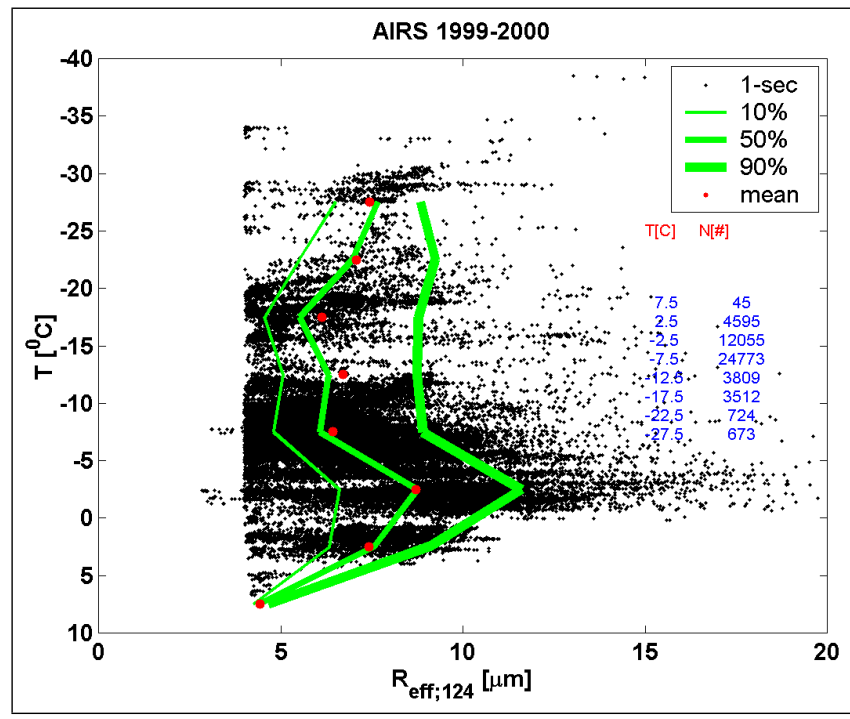

Fig. 6. Effective size as a function of temperature. The number of points is also shown on the figure.

and this can be shown using the following equation (Gultepe et al., 1996):

$r_{\text {eff }}=\left(3 \mathrm{LWC} / 4 \pi \rho_{w} k N_{d}\right)^{1 / 3}$,

where $\rho_{w}$ is the density of water droplets and $k=r_{\mathrm{mvr}}^{3} / r_{\mathrm{eff}}^{3}$, represents a ratio between the mean volume radius (mvr) and effective radius. The $k$ value here is taken as 0.7 for AIRS although its range changes between 0.65 for clouds over land and 0.81 for clouds over the ocean (Gultepe et al., 1996). Martin et al. (1994) stated that the peak size of droplets at cloud top for continental clouds is smaller than in the maritime case, and they found $k=0.67$ and 0.80 for the continental and maritime clouds, respectively. Wood and Field (2000) also stated that increasing $N_{d}$ was related to increasing $N_{a}$. These studies suggested that the use of a constant value for $k$ can significantly affect the ability to obtain an accurate $r_{\text {eff }}$ from LWC and $N_{d}$ values. Using Figs. 2 and 5 where $\mathrm{LWC}=0.2 \mathrm{~g} \mathrm{~m}^{-3}\left(N_{d}=200 \mathrm{~cm}^{-3}\right)$ at $T 1$ and $0.03 \mathrm{~g} \mathrm{~m}^{-3}\left(50 \mathrm{~cm}^{-3}\right)$ at $T 2, r_{\text {eff }}$ is calculated at two levels e.g. $T 1=-5^{\circ} \mathrm{C}(7.0 \mu \mathrm{m})$ and $T 2=-20^{\circ} \mathrm{C}(5.9 \mu \mathrm{m})$. While $N_{d}$ and LWC at $T 2$ were reduced by $75 \%$ and $85 \%$, respectively, with respect to $T 1, r_{\text {eff }}$ was reduced by $15 \%$ for the same temperature interval. This demonstrates that uncertainties related to $r_{\text {eff }}$ obtained from Eq. (1) can be large when $k$ is assumed as a constant.

A parameterization of $N_{d}$ versus $T$ can be useful to estimate the effective size from Eq. (1). For this purpose, $N_{d}$ was averaged over $5^{\circ} \mathrm{C}$ intervals, and a best fit was obtained for the entire data set including AIRS, RACE, and FIRE.ACE. The equation for the best fit in Fig. 5 is obtained as

$N_{d}=-0.071 T^{2}+2.213 T+141.56 \quad \mathrm{R}=0.91$.

Equation (1) together with LWC-T and $N_{d}-T$ (Eq. 2) parameterizations can be used to estimate $r_{\text {eff }}$ values in the mass conservation equations of the GCMs.

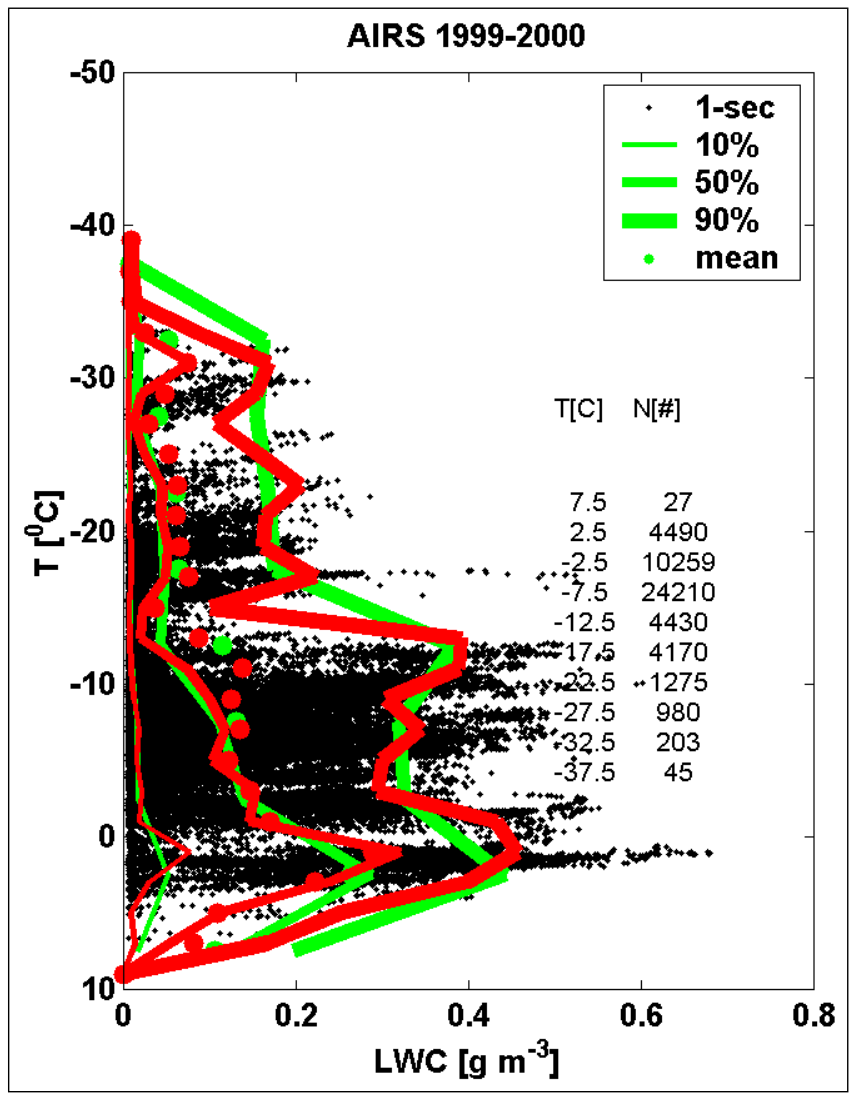

Fig. 7. Comparison of $\mathrm{LWC}$ values averaged over $5^{\circ} \mathrm{C}$ intervals (green lines) and $2^{\circ} \mathrm{C}$ intervals (red lines). The black dots are for observations from the AIRS field project.

Figure 6 for AIRS shows that the mean (median) $r_{\text {eff }}$ does not show a consistent trend with temperature. At the coldest and warmest temperatures, possible trends should be discounted because of the limited data set. The RACE $r_{\text {eff }}$ profile did not show large changes $(6-7 \mu \mathrm{m})$ because the data covered a smaller $T$ interval (not shown) as compared to that of AIRS. The analysis indicated that $r_{\text {eff }}$ values obtained from AIRS observations were comparable to those given in Table 3, which were obtained using Eq. (1) and the mean LWC and $N_{d}$. The mean absolute difference between the observations and calculations is estimated at about $0.35 \mu \mathrm{m}$.

Effective radius is also related to cloud physical thickness, breadth of the particle spectra, LWC, droplet number concentration and the available cloud condensation nuclei. The parameterization of $r_{\text {eff }}$ or $N_{d}$ versus $T$ can be affected by the physical parameters and spectral breadth (Martin et al., 1994; Wood and Field, 2000). When clouds become convectively active, the microphysical parameters are influenced by vertical air motion. Increased vertical motions result in larger droplets, and consequently $r_{\text {eff }}$ becomes larger. This suggests that stratiform clouds with embedded cells may have larger $r_{\text {eff }}$ as compared to those without cells. It is not well known how turbulence affects the development of particle spectra but a study by Kato et al. (2001) suggested that increased turbulent motions might also result in large droplets (large 
Table 3. Effective radius calculated from AIRS observations and from Eq. (1) that utilized $k,=0.72$, mean LWC and $N_{d}$

\begin{tabular}{cccccc}
\hline$T\left[{ }^{\circ} \mathrm{C}\right]$ & $\begin{array}{c}\text { LWC } \\
\mathrm{g} \mathrm{m}^{-3}\end{array}$ & $\begin{array}{c}N_{d} \\
\mathrm{~cm}^{-3}\end{array}$ & $\begin{array}{c}\text { Mean estimated } \\
r_{\mathrm{eff}}[\mu \mathrm{m}]\end{array}$ & $\begin{array}{c}\text { Mean observed } \\
r_{\mathrm{eff}}[\mu \mathrm{m}]\end{array}$ & $\begin{array}{c}\text { Difference between } \\
r_{\mathrm{eff}} \text { 's }[\mu \mathrm{m}]\end{array}$ \\
\hline 2.5 & 0.207 & 200 & 7.1 & 7.41 & 0.31 \\
\hline-2.5 & 0.139 & 100 & 7.8 & 8.72 & 0.92 \\
\hline-7.5 & 0.128 & 200 & 6.0 & 6.43 & 0.43 \\
\hline-12.5 & 0.105 & 150 & 6.2 & 6.71 & -0.47 \\
\hline-17.5 & 0.064 & 75 & 6.6 & 6.13 & 0.68 \\
\hline-22.5 & 0.039 & 50 & 6.4 & 7.08 & 0.05 \\
\hline-27.5 & 0.035 & 30 & 7.4 & 7.45 & \\
\hline
\end{tabular}

effective sizes).

\subsection{Sensitivity to temperature interval}

In order to test the sensitivity of the analysis to the width of the temperature interval, the analysis was done for both $5^{\circ} \mathrm{C}$ and $2^{\circ} \mathrm{C}$ intervals. Figure 7 shows profiles of $5^{\circ} \mathrm{C}$ and $2^{\circ} \mathrm{C}$ averaged values of LWC versus $T$. The values at $2^{\circ} \mathrm{C}$ intervals give greater fluctuations at a given level. Averaging (also $50 \%$ value) of LWC in the vertical over $2^{\circ} \mathrm{C}$ intervals as compared to those at $5^{\circ} \mathrm{C}$ intervals results in an approximately $0.025 \mathrm{~g} \mathrm{~m}^{-3}$ change at the same level. Differences in the $20 \%$ and $80 \%$ values over two averaging intervals at the same level are much larger than those seen in median values, and variability in the percentile and median values are larger at colder temperatures. $N_{d}$ values at $2^{\circ} \mathrm{C}$ intervals also had larger variances as compared to those at $5^{\circ} \mathrm{C}$ intervals (not shown). However, the general trends were not significantly different. These results suggest that variability of LWC and $N_{d}$ should be considered in the climate simulations.

\section{Conclusion}

The main conclusions from this work are summarized as follows:

- The LWC-T relationships from the three projects were found to agree with those of GI and Mazin (1995), with LWC decreasing with $T$. Overall, for stratiform clouds, the LWC- $T$ relationship was found to be consistent in several different research projects, and was relatively independent of geographical region and season.

- LWC and $N_{d}$ values can vary over a considerable range within the same temperature interval. When a GCM model is used, this variability can affect the net cloud radiative forcing about $\pm 10 \mathrm{~W} \mathrm{~m}^{-2}$.
- Averaging scales should be considered in the climate simulations especially when the grid size or measurement averaging interval is less than $15 \mathrm{~km}$.

- A difference between averaged values (also median values) of $\mathrm{LWC}$ at the same level, based on $2^{\circ} \mathrm{C}$ and $5^{\circ} \mathrm{C}$ averaging intervals, is approximately $0.025 \mathrm{~g} \mathrm{~m}^{-3}$, and this difference can be significant in climate studies, especially at cold temperatures.

- A relationship between $N_{d}$ and $T$ has been proposed and this may improve the calculation of $r_{\mathrm{eff}}$ and optical parameter calculations in GCM simulations, rather than assuming that $N_{d}$ is a constant or a function of aerosol number concentration.

The present work summarizes the parameterizations of LWC and $N_{d}$ versus $T$ that are important for cloud and climate studies. The $N_{d}$ versus $T$ plots indicated that $N_{d}$ decreases with decreasing $T$, while LWC also decreases with decreasing $T$. $N_{d}$ should not be assumed to be constant, and the variability of $N_{d}$ and LWC should be considered in GCM applications.

Acknowledgements. The Panel on Energy Research and Development provided financial support for RACE and FIRE.ACE. Additional support was given from NASA for the collection of the FIRE.ACE data. The National Search and Rescue Secretariat of Canada, Boeing Commercial Airplane Group, Transport Canada, and the Department of National Defense provided funding for the AIRS project. The aircraft data were obtained using the National Research Council of Canada Convair-580 and the scientific and technical efforts of many National Research Council and Meteorological Service of Canada staff. The authors thank J. W. Strapp for discussions related to the data analysis.

Topical Editor J.-P. Durel thanks two referees for their help in evaluating this paper. 


\section{References}

Baumgardner, D., Cooper, W. A., and Dye, J. E.: Optical and electronic limitations of the forward scattering spectrometer probe, Liquid Particle Size Measurements Techniques: 2nd Vol., ASTM STP 1083, (Eds) Dan Hirleman, E., Bachalo, W. D., and Felton, P. G., American Society for Testing and Materials, Philadelphia, 115-127, 1990.

Betts, A. K. and Harshvardhan: Thermodynamic constraint on the cloud liquid water content feedback in climate models, J. Geophy., Res., 92, 8483-8485, 1987.

Cober, S. G., Isaac, G. A., and Strapp, J. W.: Characterizations of aircraft icing environments that include supercooled large drops, J. Appl. Meteor., 40, 1984-2002, 2001a.

Cober, S. G., Isaac, G. A., Korolev, A. V., and Strapp, J. W.: Assessing cloud-phase conditions, J. Appl. Meteor., 40, 1967-1983, 2001b.

DelGenio, A. D., Yao, M. S., Kovari, W., and Lo, K. K. W.: A prognostic cloud water parameterization for global climate models, J. Climate, 9, 270-304, 1996.

DelGenio, A. D. and Wolf, A. B.: The temperature dependence of the liquid water path of low clouds in the southern great plains, J. Climate, 13, 3465-3486, 2000.

Feigelson, E. M.: Preliminary radiation model of a cloudy atmosphere. Part I: Structure of clouds and solar radiation, Beitr. Phy. Atmos., 51, 203-229, 1978.

Ghan, S. J., Chuang, C., and Penner, J. E.: A parameterization of cloud droplet concentration. Part I: Single aerosol type, Atmos. Res., 30, 197-221, 1993.

Gultepe, I., Isaac, G. A., Leaitch, W. R., and Banic, C. M.: Parameterization of marine stratus microphysics based on in situ observations: Implications for GCMs, J. Climate, 9, 345-357, 1996.

Gultepe, I. and Isaac, G. A.: Liquid water content and temperature relationship from aircraft observations and its applicability to GCMs, J. Climate, 10, 447-452, 1997.

Gultepe, I. and Isaac, G. A.: Scale effects on averaging of cloud droplet and aerosol number concentrations: observations and models, J. Climate, 12, 1268-1279, 1999.

Gultepe, I., Isaac, G. A., and Cober, S. G.: Ice crystal number concentration versus temperature for climate studies, Inter. J. of Climatology, 21, 1281-1302, 2001a.

Gultepe, I., Isaac, G. A., and Strawbridge, K.: Variability of cloud microphysical and optical parameters obtained from aircraft and satellite remote sensing during RACE, Inter. J. Climate, 21, 4, 507-525, 2001b.

Gultepe, I. and Isaac, G. A.: The effects of air-mass origin on Arctic cloud microphysical parameters during FIRE.ACE, J. Geophy. Res., in press, 2002.
Isaac, G. A., Cober, S. G., Strapp, J. W., Korolev, A. V., Tremblay, A., and Marcotte, D. L.: Recent Canadian research on aircraft in-flight icing, Canadian Aero. Space J., 47, 213-221, 2001.

Kato, S, Mace, G. G., Clothiaux, E. E., Liljegren, J. C., Austin, R. T.: Doppler radar derived size distributions in liquid water stratus clouds, J. Atmos. Sci., 58, 2895-2911, 2001.

Kiehl, J. T. and Ramanathan, V.: Comparison of cloud radiative forcing derived from the earth radiation budget experiment with that simulated by NCAR community climate model, J. Geophy. Res., 95, 11 679-11 698, 1990.

Korolev, A. V., Strapp, J. W., Isaac, G. A., and Nevzorov, A.: The Nevzorov airborne hot wire LWC/TWC probe: Principles of operation and performance characteristics, J. Atmos. Ocean. Tech., 15, 1496-1511, 1998.

Korolev. A. V., Isaac, G. A., Mazin, I. P., and Barker, H.: Microphysical properties of continental stratiform clouds, Q. J. Roy. Met. Soc., 127, 2117-2151, 2001.

Lemus, L., Rikus, L., Martin, C., and Platt, R.: Global cloud liquid water path simulations, J. Climate, 10, 52-64, 1997.

Liou, K. N. and Ou, S. C.: The role of cloud microphysical processes in climate: An assessment from a one-dimensional perspective, J. Geophy. Res., 94, 8599-8607, 1989.

Martin, G. M., Johnson, D. W., and Space, A.: The measurement and parametrization of effective radius of droplets in warm stratocumulus clouds, J. Atmos. Sci., 51, 1823-1842, 1994.

Mazin, I. P.: Cloud water content in continental clouds of middle latitudes, J. Atmos. Res., 35, 283-297, 1995.

Meyers, M. P., DeMott, P. J., and Cotton, W. R.: New primary icenucleation parameterizations in an explicit cloud model, J. App. Meteor., 31, 708-721, 1992.

Platt, C. M. R.: The role of cloud microphysics in high cloud feedback effects on climate, Nature, 341, 428-429, 1989.

Rasch, P. J. and Kristjansson, E.: A comparison of the CCM3 model climate using diagnosed and predicted condensate parameterizations, J. Climate, 11, 1587-1614, 1998.

Rotstayn, L. D.: Climate sensitivity of the CSIRO GCM: Effect of cloud modelling assumptions, J. Climate, 12, 334-356, 1999a.

Rotstayn, L. D.: Indirect forcing by anthropogenic aerosols: A global climate model calculation of the effective-radius and cloud-lifetime effects, J. Geophy, Res., 104, 9369-9380, 1999 b.

Slingo, A. and Schrecker, H. M.: On the shortwave radiative properties of stratiform water clouds, Quart. J. Roy. Meteor. Soc., 108, 407-426, 1982.

Smith, R. N. B.: A scheme for predicting layer clouds and their water content in a general circulation model, Quart. J. Roy. Meteor. Soc., 116, 407-426, 1990.

Wood, R. and Field, P. R.: Relationships between total water, condensed water, and cloud fraction in stratiform clouds examined using aircraft data, J. Atmos. Sci., 57, 1888-1905, 2000. 